\title{
Knowledge forms in the project lifecycle: A blueprint for knowledge management in small creative agencies in Johannesburg
}

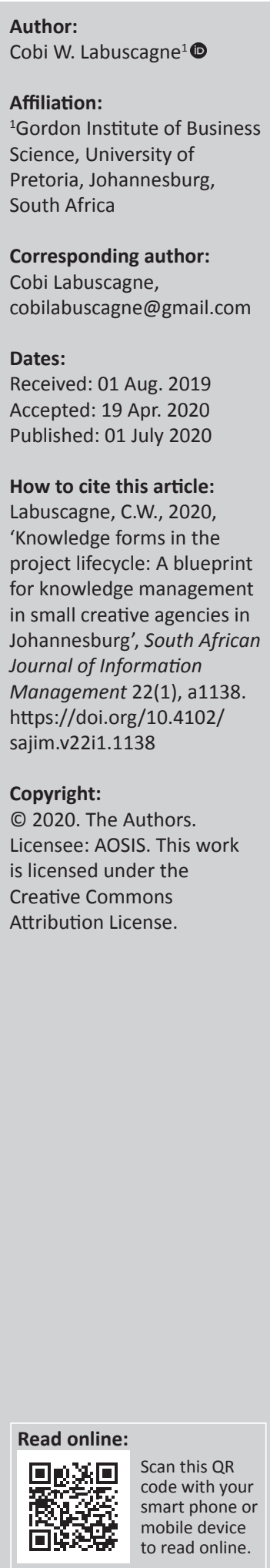

Background: Knowledge-intensive Organisations (KIO) are heavily reliant on the creation, communication and archiving of different forms of knowledge for their survival. Many KIOs that are creative agencies organise their workflows according to projects. Each phase of a project produces distinct forms of knowledge. Understanding the variations in the demands on knowledge management (KM) in step with changes in knowledge forms in different project lifecycle phases allows for the development of appropriate KM.

Objectives: The research set out to use the project lifecycle in Small and Medium-sized Enterprises (SME) KIO creative agencies as an organising device for outlining different knowledge forms at each phase. The objective was to map KM forms onto the knowledge forms in each project phase.

Method: A qualitative research approach with phenomenological research design was used. The empirical site was at eight organisations in Johannesburg, South Africa in the creative industries. The data was analysed using content analysis.

Results: There are dramatic changes in knowledge forms at different points in a typical project lifecycle in SME KIO. However, the stages of a project are replicable and consistent between most of the projects that were analysed.

Conclusion: A strategy for mitigating against knowledge loss in SME KIO creative agencies is to use a range of different $\mathrm{KM}$ that are appropriate to the forms of knowledge. Using the project phases as a blueprint can lead to more accurate forms of KM at each distinct stage in the project lifecycle.

Keywords: knowledge management; knowledge-intensive organisations; creative agencies Johannesburg; project lifecycle; knowledge forms; knowledge management forms.

\section{Introduction}

Knowledge-intensive Organisations (KIO) have recognised the need to safeguard against knowledge loss. This is especially true in creative agencies where there is a high level of reliance on the knowledge brought by key individuals in a team. This knowledge often resides in the key team members themselves and is of a particularly tacit nature. The danger of knowledge loss when employees leave is real to all organisations (Khoza 2019) but might be said to be more severe in Small and Medium-sized Enterprises (SME) KIO creative agencies. Additionally, there is a disregard for formal knowledge management (KM) systems in many SME KIO and an overreliance on 'remembering' (Cerchione \& Esposito 2017). Working conditions are often fast-paced coupled with a pressure to move straight onto the next project once the present one is completed. It is necessary to develop KM tactics for storing and retrieving knowledge to the best of the firm's abilities. Many KIOs organise their workflows according to projects. Each phase of a project produces distinct forms of knowledge. When considering the variation in knowledge forms at different phases in a typical project lifecycle, it becomes possible to attune the KM options to the knowledge forms. The study proposes to use the project lifecycle as a blueprint for a combination of KM forms comprising of narrativisation, visualisation and information systems (IS).

Knowledge-intensive Organisations is a broad term to reference businesses that offer nonutilitarian services (Marin, Cordier \& Hameed 2016), and creative agencies can be seen as a subsection that focusses on, for example, art, design, entertainment, and advertising (Lampel, Lant \& Shamsie 2000). This research is situated in this sub-section of KIOs. The KIOs that this study looked at were also SMEs. 
This research uncovered four tendencies in the KM relationship in SME KIO creative agencies: (1) On deadline behaviour typically pushes reflection to the back. (2) A disregard for new systems of working if the benefit is not immediate. (3) Some forms of spontaneous KM taking place in an ad hoc manner. (4) A desire to better manage knowledge to safeguard against knowledge loss which might lead to the loss of clients.

\section{Aims and research applicability}

This research aims to name the different knowledge forms that are present at different points in a project lifecycle, and to map KM forms onto those phases. As Nissen (2002) points out, it is not enough or effective to simply introduce IS for KM to automate an existing practice. Rather, '... the organisation, people, procedures, culture and other factors need to be considered in addition to technology' (Nissen 2002:256). Potgieter, Dube and Rensleigh (2013) mention the importance of positive adoption by the employees of any suggested KM system. When the $\mathrm{KM}$ is considered in relation to the knowledge forms it is likely to feel more natural to the team.

The research aims, furthermore, to produce empirical insights into how creative organisations create and manage knowledge while focussing on a project lifecycle. The specific focus on the project lifecycle grounds the research in the practicalities of the work-life in KIO SME creative agencies, which can be adapted and used for other types of organisations.

Lastly, a point of departure in this research is that a better understanding of the different aspects of $\mathrm{KM}$ can add to management practices (Roblek et al. 2013), as well as competitive advantage (Krylova, Vera \& Crossan 2016; SotoAcosta \& Cegarra-Navarro 2016; Steinmueller 2000). In this way the research aims to have application beyond the specific geography and industry discussed here.

\section{Problem statement}

How can SME KIO better safeguard themselves against knowledge loss? Can the project lifecycle be used to better attune KM for SME KIO to knowledge forms? Some scholars have looked at this question in the fields of construction and engineering and have also used the project lifecycle as an entry point (Sagsan 2006). Those kinds of projects are often large scale, and many actors are involved. Knowledge loss in the small creative agency brings on a different set of challenges that not only weighs on the success of the project itself, but can jeopardies the very survival of the business. Baptista Nunes et al. (2006) opine that SMEs do not see the value of $\mathrm{KM}$ and are overtly focussed on the immediate gain that knowledge can give, rather than being future focussed.

Coexisting with this attitude of disregard for KM, this research has found certain structures to be in place to gather knowledge as and when it is needed. This observation concurs with what Cerchione and Esposito (2017) found when creating a taxonomy of KM used in SMEs. They observed that certain KM practices were in place that could be turned into a more coherent KM system. This paper argues that the project lifecycle can be used to tailor the KM with the knowledge forms, thereby, some of the practices that are already in place can be mapped onto the knowledge forms that different stages in the project lifecycle present.

Many KIO creative agencies operate on projects (Farzaneh \& Shamizanjani 2014; Lapunka \& Pisz 2014). A project has been defined by the Project Management Institute as 'temporary', 'unique', and in need of 'expert management' to 'deliver the on-time, on-budget results' (2018). In the respondents for this study, examples of projects were: the launch and roll out of an advertising campaign; an art auction; a trade fair; a new line of clothing. The focus of the project lifecycle adds to this study a grounding in the everyday reality of KIO creative agencies.

\section{Literature review}

Knowledge-intensive Organisations, as noted earlier, is a broad term to reference those that offer non-utilitarian services (Lampel et al. 2000; Marin et al. 2016), which include financial institutions, law, technology companies, and many creative industry businesses. Lampel et al. (2000), as well as Lawrence and Phillips (2002), argue that the sub-sector within this grouping of creative agencies, which include art, advertising, fashion, and design is under-investigated.

For Garrick and Chan (2017) the importance of creative agencies is immense, in that they have the power to shape, influence and affect audiences. These authors opine that the high levels of creativity present in these organisations, and their unique ways of dealing with managerial issues might be of use to other businesses faced with the challenge of creative innovation. It is also possible that, given their flexibility, SME KIO might be dealing with complex organisational problems faster than larger ones can (Lampel et al. 2000). Baptista Nunes et al. (2006) describe these types of organisations as having high levels of creativity, problem solving and highly educated employees. Millar, Lockett and Mahon (2016) make the bold claim that when knowledgeintensive organisations fail to capture knowledge it becomes useless and lost.

Knowledge management has been a thriving research field for some decades now (Alavi \& Leidner 2001; Teece 1998). Baptista Nunes et al. (2006) define knowledge management as how knowledge is 'generated, represented, stored, transferred, transformed and applied to future organisational problems' (p. 102). Knowledge management theory have evolved as organisational natures have changed. Recent work has turned to Web 2.0, and found it has opened up new knowledge management challenges (Roblek et al. 2013; Soto-Acosta \& Cegarra-Navarro 2016). There is also a growing body of work that looks at more abstract concepts in relation to $\mathrm{KM}$, such as experimentation (Krylova et al. 2016); the importance of team construction 
(Savino, Petruzzelli \& Albino 2017); performativity (Marin et al. 2016), and the importance of improvisation (Pina e Cunha \& Da Cunha 2006).

Despite this diversity of writing on $\mathrm{KM}$, there is very little attention given to KM needs as they change in fundamental ways, during the course of a project lifecycle. Furthermore, while a considerable proportion of attention has been given to different KM options, it is still hard to determine which knowledge forms benefit from IS and which need other ways of management. Accordingly, some existing literature on KM suffers from linearity that does not take into account the dynamic nature of knowledge as changing in form and function. Diedrich and Guzman (2015) point out that, traditionally, academics in KM studies have not considered 'procedural' and 'contextual' factors (p. 1274). Additionally, while the concepts of explicit and tacit knowledge (Nonaka \& Takeuchi 1995), elaborated on below, have been given much attention, there is little that dissect these terms to be more accurately descriptive.

Many studies on KM begin by creating an appropriate definition of knowledge (Nevo \& Chan 2007). Taylor and Zorn (2004) distinguish between data, information, knowledge and wisdom as building on top of one another, with 'human interpretation and judgment' creating links between the concepts (p. 11). Taking a similar stance, Alavi and Leidner (2001) explain that information provides a new version of knowledge once it has been understood by a person. This study applies the definitions by both Taylor and Zorn (2004), and that by Alavi and Leidner (2001).

A key work attempting to position knowledge in business practice is that by Nonaka and Takeuchi (1995). These authors mobilise the findings that knowledge exists on two levels: the first is explicit, or codified knowledge; and the second is tacit, or uncodified knowledge. Academic literature offers other terms for these knowledge distinctions. Madhavan and Grover (1996) speak of embedded versus embodied knowledge and Roberts (2000) mentions the difference between know-how and show-how. While many scholars have built on Nonaka and Takeuchi's (1995) seminal, qualitative work (Alavi \& Leidner 2001), some writers have fundamentally disagreed (Heaton \& Taylor 2002). Tsoukas (2002), and others (Fahey \& Prusak 1998) argue that the concept of tacit knowledge as the opposite of explicit knowledge misconceives the way knowledge functions, as the concepts are two sides of the same coin (Tsoukas 2002). In this study, there is a preference for more descriptive approaches to knowledge forms that go beyond the duality created by the terms 'tacit' and 'explicit'.

\section{Forms of knowledge management}

The consideration of different forms of $\mathrm{KM}$ found in the literature is key to the research question and is used to better understand the $\mathrm{KM}$ in the organisations under investigation in this study.

\section{Information systems}

There is a long-established relationship between KM and IS that often takes precedence in general discussion around knowledge in organisations (Garrick \& Chan 2017). Writing about recent phenomena, Soto-Acosta and Cegarra-Navarro (2016) consider ways in which new technology such as Web 2.0/3.0 can facilitate KM. They list specifically: 'collaboration technologies, social networking tools, wikis, internal blogging' (Soto-Acosta \& Cegarra-Navarro 2016:417). However, some scholars have questioned how well IS and $\mathrm{KM}$ is working and how the value can be measured (McDermott 1999; Roberts 2000). In most writing on IS and $\mathrm{KM}$ there is a single focus on one type of IS or one type of $\mathrm{KM}$, and so the theory is falling short on offering more comprehensive solutions. Furthermore, none of the above examples from literature focusses on creative agencies, and so there is a further opportunity to enlarge the theoretical span of writing on KM and IS options.

\section{Narrativisation}

Farzaneh and Shamizanjani (2014) suggest one can use storytelling to convey and manage knowledge. They argue that a story is imbedded in contextual and experiential information, which makes it potentially, more memorable. According to these authors, stories could be ways of combining emotion and values within a task-based situation such as a project. Krylova et al. (2016) also propose storytelling as the relaying of experience. Narratives are thus informal archives of what might happen, given what has happened before. Authors have not combined the suggestion to narrativise knowledge with other forms of KM to see if there might be an ecosystem of KM at play. It is within this gap that the present research positions itself.

\section{Visualising}

A stream of writing exists that considers ways of visualising knowledge. This form of KM fits particularly well with the work done in KIO creative agencies. Examples include the research by Ambrosini and Bowman (2001) who argue that the way of extracting knowledge is through specific tactics to do with 'cognitive mapping' (Ambrosini \& Bowman 2001:817). Eppler and Burkhard (2007) refer to this process as 'knowledge visualisation', the main aim of which is to 'transfer insights, experiences, attitudes, values, expectations, perspectives, opinions and predictions ... enable(ing) someone else to reconstruct, remember, find or apply these insights correctly' (pp. 122-123). Visualisation is a process that might well naturally take place within a project. However, it might not be a fit-all answer to understanding all the forms of knowledge that come into play in a project lifecycle.

\section{Research methods and design}

This study employed a phenomenological, qualitative methodology. Creswell and Poth (2018) characterise phenomenology as strongly connected to the researcher who is intent on representing a particularity of the lived world. 
Accordingly, ingredients include 'assumptions', 'a situation', 'meaning', 'voices of participants', and 'reflexivity' (Creswell \& Poth 2018:37).

\section{Research context and setting}

This research is positioned within the context of the South African creative industries, which can also be referred to as creative agencies (Lampel et al. 2000). South African, Van Graan (2005), in a White Paper for the Department of Economic Development and Tourism elaborates on this sector in the following way:

Creative Industries are those areas of social and economic activity that are premised on - or closely aligned with - a) individual or collective intellectual or artistic creativity, innovation and originality and/or b) the preservation, teaching and celebration of cultural heritage including language and which have the capacity to provide work and generate income for the original creators as well as for others involved in education and training production, distribution, documentation and support for creative products or cultural experiences, whether in a not-for-profit capacity or for commercial gain. (p. 6)

\section{Unit of analysis}

The research aimed to understand KM and knowledge forms in the KIO creative agencies that are SMEs, and so it was felt that more than one organisation should be brought into the data-gathering process. Interviews took place with eight respondents. Specific requirements for businesses to be chosen as respondents included:

- An organisation focussed on cultural products

- An SME

- An organisation that structure workflow via projects.

Requirements for interview candidates included:

- An owner, manager or director

- In employment with the organisation for more than 8 years

- Multiple years of experience in the field

- An ability to articulate complex concepts relating to the topic

- Available for more than one interview.

\section{Sampling}

\section{In-depth semi-structured interviews}

The research questions ask for interpretative answers that are based on experience. For that reason, in-depth semistructured interviews were appropriate (Easterby-Smith, Thorpe \& Jackson 2012). Questions were targeted to answer the research question, but were left open-ended. Questions included:

- Please describe your project lifecycle

- How do you view knowledge management in organisations in general?

- Do you think you are retaining knowledge well at the moment?
Peer recruitment was used to identify respondents and to ensure a group that was independent of the researcher. After a process of cultivating interest in the project via email, consent forms were sent and interview dates were set. Interviews lasted between 45 and $90 \mathrm{~min}$. Semi-structured interview questionnaires guided the discussion. However, the respondents were encouraged to speak freely and not be concerned if their responses felt like 'rambling'. In this way, broad themes might start to emerge that could not have been anticipated when the interview guidelines were created (Kissling Hansen 2009).

\section{Focus groups}

Focus groups were conducted in one of the organisations as a way of questioning some of what was emerging from the data. Two sessions were conducted with seven team members present. It was important in these sessions to get the full team who administered the entire lifecycle of a project present. This could only be achieved in one of the respondent organisations. It was useful to have more than one session as the data and findings could be double-checked with the same team at two different points in the analyses to ascertain to what extent the findings were reflecting their experience. In these sessions a fictional scenario was created to get the organisation's project team to actively engage in thinking about the knowledge at different points in a project. The project team was asked what forms of knowledge would be required if the organisation was to open an office in another country. This fictional paradigm was a device to allow the process of 'cognitive mapping' to take place (Ambrosini \& Bowman 2001:817).

\section{Data analysis}

Given the phenomenological nature of the inquiry and the ontology of relativism, it was appropriate to approach the data inductively and there was a consideration of complexity, contingencies and interactions of different data points. The research questions demanded content analyses of the data (Easterby-Smith et al. 2012). There was also sensitivity for what was happening around the interview data, for example, the setting, the industry and the dynamic in the interview process.

\section{Validity and reliability}

The research followed steps towards validity and reliability of the data. These processes can be summarised as:

- Key informers were returned to for presentation and discussion of findings.

- All informers have experience and are of good standing in the industry.

- The researcher addressed her proximity and possible biases through focus groups where results were presented and discussed.

\section{Ethical consideration}

Before the interview process, consent letters and information on the subject of study was circulated, ensuring upfront 
TABLE 1: List of respondents.

\begin{tabular}{|c|c|c|c|c|c|}
\hline Company & Team size & Projects per year & Years in business & Clients & Types of projects \\
\hline Trade Fair agency & 6 & 4 & 12 & $\begin{array}{l}\text { Corporates, government and high } \\
\text { net-worth individuals }\end{array}$ & Annually recurring trade fairs \\
\hline Advertising agency & 10 & More than 10 & 20 & Corporates and government & $\begin{array}{l}\text { Creative branding, communications and marketing } \\
\text { campaigns and activations }\end{array}$ \\
\hline Auction agency & 10 & More than 10 & 3 & High net-worth individuals & Monthly auctions \\
\hline Communications agency & 5 & 5 & 3 & Corporates & Communications and activation campaigns \\
\hline Art NGO & 20 & More than 10 & 20 & $\begin{array}{l}\text { Business leaders and other creative } \\
\text { agencies }\end{array}$ & Awards, conferences and research \\
\hline Jewellery brand & 2 & 5 & 15 & Public & Exhibitions and fairs \\
\hline Clothing brand & 2 & More than 10 & 3 & Public & $\begin{array}{l}\text { Launching, marketing and selling new clothing } \\
\text { ranges }\end{array}$ \\
\hline Graphic design agency & 5 & More than 10 & 7 & Corporates & Small-scale design, digital and marketing activations \\
\hline
\end{tabular}

NGO, non governmental organisations.

ethical clearance. This article followed all ethical standards for a research without direct contact with human or animal subjects.

\section{Results}

\section{Presentation of the data}

The presentation of the data here follows the suggestion for phenomenological studies outlined by Creswell (2007).

\section{Personal experience bracketing}

The researcher worked as an owner/manager for over a decade in an organisation operating as a KIO SME creative agency in Johannesburg. Upon entering the field the intention was to bring past experience to the fore. However, as the data gathering progressed, the relative weight shifted to the experience of the respondents and what came through in the interviews.

\section{Descriptions of the setting}

Creative agencies are emotive places of work that thrive on creativity (Lampel et al. 2000). Imagine a workplace that is filled with energy, passion and opinions. Within this setting it is tangible that this passionate energy and these opinions are the fuel that makes the engine run. The working environment is colourful and inventive and there is a fast pace of work. There are communal working spaces and discussions are taking place. The workforce is diverse, including multiple generations, races and genders.

The above is a portrait of a typical SME KIO creative agency in South Africa. For this study a broad range of these small creative agencies were approached, and these are summarised in Table 1.

Following the guidelines set by the Project Management Institute (2018), four distinct project lifecycle phases were identified. These were:

- Development phase

- Planning phase

- Execution phase

- Evaluation phase

\section{Description of project lifecycle phases}

The development phase could take the form of a response to a tender, a new range of clothing, or a proposal to win a new client. Some projects were annually recurring in which case the development phase marked the period where innovation and 'new-ness' for the coming iteration was discussed and developed. This phase was heavily collaborative. Team members had brainstorming workshops and some elements of research on trends or the behaviour of competitors informed the process.

In contrast to the 'development phase', planning was more passive in that it happened individually, followed by recurring status meetings where planning and progress was assessed. Planning involved timeline, budget and resource allocation. It was not a phase that demanded direct experience, since many of the aspects were merely adapted from previous projects. This phase is thus well documented and archived as the below quote from a respondent illustrates:

We put everything on Google, and then it sits there. So, for instance, every single budget, every single recon of that budget, so what we actually spent, where, the suppliers on that project Every single proposal, strategy - is all in Google Docs. And we tap into those budgets and those things all the time. (Anonymous 1, pers. comm., 17 January 2018)

By its nature the execution phase was 'out of the office' for the members of the KIO SME that was interviewed for this study. In execution a project takes place or is 'rolled out'. Execution also encompassed the marketing and sales aspects of the project and so the focus was external to the organisation. Projects took many different forms, as is outlined in Table 1 above.

The review phase was the only one of the four identified stages that was actively associated with KM. There was often an attempt to 'remember' and capture everything that had happened throughout the different project phases. The review typically took the form of a debrief where all the project team members were present and tended to revolve around points of unhappiness in the process. Accordingly, it was more focussed on what went wrong and could be an emotional session. There was pressure to rapidly move on to the next project and not get around to doing any formal 
archiving. What this practice translated into, was KM that were purely document related and lacked narrative and visual information that other forms of KM offer. Many of the organisations interviewed had to do an external review for clients. This took the form of surveys, videos and narratives of what happened. These documents were created with the client in mind, however, often the best form of post project review that they engaged with.

\section{Discussion}

\section{Key findings}

- It was found that project lifecycle phases can be used as a guideline for more effective KM. The project lifecycle was a successful research focus to delineate and isolate forms of knowledge and corresponding forms of KM. It was found that the project lifecycle was useful as a focal structure for respondents, as it forced them to think very specifically about 'what they did', 'what they needed in order to do what they did' and what the knowledge form was at each phase in the lifecycle.

- It was clear from the data that there is a high risk of knowledge loss in small creative agencies due to a number of factors:

- small teams rely heavily on spontaneous decisionmaking

- reluctance to spend time recording due to high demands of the project client

- over-reliance on team member trust

- over-reliance on key person permanency.

All of these 'obstacles' can be managed by systematically reviewing the knowledge forms being produced and relied on at each stage in a project lifecycle and suggesting appropriate forms of $\mathrm{KM}$ for each stage. The suggestion is to imbed the KM in the project phase itself in as natural a way as possible.

- Different forms of knowledge demand different forms of $\mathrm{KM}$ that attune more naturally to the project lifecycle phase. The KM system should comprise of narrativisation, visualisation and IS options. This is illustrated in Table 2 below.

\section{Discussion of key findings}

\section{Knowledge management in the project lifecycle}

Development Phase knowledge management: The knowledge form characteristic of this phase was an idea or a concept. Team members relied on creativity, innovation and experience. The quotation below from one respondent emphasises the degree to which the knowledge is tacit and personal:

It's been a dream of mine. ... To have vocations in fields that I love and that I am passionate about. Because of this I can bring all my knowledge of pictures, beauty, clients and design together in my business. (Anonymous 2, pers. comm., 17 December 2017)

The most appropriate form of KM would be narrativisation. This would entail a commitment to recording, in narrative form, how the ideas were come by for the new project and how they were seen to be new, innovative and fitting the brief. This KM could take place as brainstorm meetings happen, or after the ideas have been crystallised in the form of interviews and active mentorships. These can then be turned into 'development phase case studies'. The quotation below illustrated the need for this kind of documenting:

Every time we do end up having a piece of potential new business, we scramble around and think, when last did we use a credential document? We better update it. And so it would be much better to have live, fresh case studies. But to be honest, it falls by the wayside, because our clients are the priority, not us. (Anonymous 3, pers. comm., 02 December 2017)

Visualisation maps can be used to illustrate the process whereby an idea is formed. This form of KM should take place in the moment when ideas are discussed, rather than after the fact.

\section{Planning phase knowledge management}

Most befitting to the knowledge form existing in this phase are IS options of document sharing, team collaboration tools and social enterprise development, given that much information is recycled. In this phase it was observed that budgets were re-used and changed, timelines were adapted from pervious projects and applied to the current needs, and resource allocation documents were adjusted from previous projects. Collaboration tools should streamline this process while simultaneously archiving the information systematically for future use.

\section{Execution phase knowledge management}

In the organisations under investigation the execution took two forms: first a process of sales and marketing took place, and thereafter the project itself 'happened'. In the marketing phase IS forms of social media played an overriding role because of its accessibility to small businesses, as well as the high adoption rate of creative individuals. The marketing often took the form of stories that were told to databases and so were already versions of KM that lived and were archived within the social media tools that were used. These included, bulk mailers, Instagram and Facebook. All of these tools can be seen as KM systems in themselves and offer analytics that offer insight into past behaviour.

When the project was rolled out, 'new knowledge' was created. For this reason a varied spectrum of KM tools should be employed to best capture the knowledge for future learning. Recording devices such as photos, video and sound recording can capture the in-the-moment nature of the knowledge that is created in this phase.

\section{Review phase knowledge management}

For most organisations the review phase was where all the KM practices were located, however, there was a rush to move on. This phase lends itself to narrativisation, as well as visualisation of what happened in the project. It is important 
that individual members of the team take time to tell the stories of what happened the way they experienced it and so take the focus off the negative aspects of the project. It is also recommended that at this point in the project all the KM from the previous three stages are collated and stored using an IS system. This could take the form of a cloud-based storage or a project collaboration tool.

The implication of choosing a particular knowledge form within a particular phase has direct bearing on the knowledge management that has to be applied. In turn, the knowledge management has to mirror the type of knowledge that the project phase produces and relies on. The KM forms, as listed in the Table 2, have been paired with the types of knowledge that have been created, given the particularities of each project lifecycle phase. It is critical that there is a relationship between the knowledge form and the KM form for it to be easily adopted by the team.

\section{Situating the findings in academic writing}

The research findings presented here depart from the conversations around tacit and explicit knowledge mobilised by Nonaka and Takeuchi (1995). The present study argues that the contemporary landscape within which organisations operate demands more descriptive and varied approaches to the life of knowledge. As such, the findings are more in line with studies that look at KM through the lenses of experimentation (Krylova et al. 2016); the importance of team construction (Savino et al. 2017); performativity (Marin et al. 2016), improvisation (Pina e Cunha \& Da Cunha 2006); and creative work environments (Ensor, Cottam \& Band 2001). However, these discussions are taken further and different forms of $\mathrm{KM}$ are attuned to knowledge forms in the project lifecycle. The research suggests that there is merit in accurately naming the knowledge forms in order to create a KM fit.

\section{Strengths and limitations}

The first strength of these findings is regional and pertains to the emerging economy of South Africa (Al-Shammari 2011). The work that the writers on knowledge, knowledge economies and KM have done have an urgent relevance to the South African context (Baltezarević, Baltezaravic \& Jovanovic 2015; Blankley \& Booyens 2010). South Africa is facing a need for a shift away from a resource and industrial economy to a knowledge economy (Du Toit 2003; Snowball 2016) to spur economic growth and offer skills to a larger workforce (Snowball 2016). For these reasons, more scholarly work and practical research are needed to inform this shift that could lead to job creation and skills upliftment (Blankley \& Booyens 2010). This study provides some groundwork for understanding SME KIO agencies in South Africa. More importantly, the research makes suggestions that could contribute to the longevity of SME KIO in South Africa.

The second strength of this study relates to business more broadly and addresses the importance of understanding knowledge and KM in KIO creative agencies in general (Scott 2005). Creative agencies and their relation to knowledge can have powerful learnings for other industries for innovation and creativity (Lampel et al. 2000; eds. Pratt \& Jeffcutt 2009). For this reason, a deeper understanding of how knowledge and $\mathrm{KM}$ function can be useful to organisations globally and cross-sectorally.

An acute focus on one industry in one country can produce research that is deep rather than broad. This choice of subject matter, together with the qualitative methodology employed, presents the possible limitation that one might read the data as only pertaining to the subject at hand. However, the findings serve to lay the groundwork for further investigation and theory creation.

TABLE 2: Knowledge management in the project lifecycle.

\begin{tabular}{|c|c|c|}
\hline Project phase & Knowledge form & KM form \\
\hline \multicolumn{3}{|l|}{ Development } \\
\hline Research & Archived material & Visualisation \\
\hline Conceptualisation & Face to face, ideas & Interviews, mentoring, narrativisation \\
\hline \multicolumn{3}{|l|}{ Planning } \\
\hline \multirow[t]{3}{*}{ Budget, task breakdown and duties assignment } & Document creation & Cloud-based document creation and archiving systems \\
\hline & & Process mapping \\
\hline & & Audio/video conferences \\
\hline \multirow[t]{3}{*}{ Internal communication } & Project collaboration tools & Cloud computing \\
\hline & & Social Enterprise Resource Planning (ERP) \\
\hline & & Peer-to-peer resource sharing \\
\hline \multicolumn{3}{|l|}{ Execution } \\
\hline External Communication & Databases & Client Relationship Management Software (CRM) \\
\hline Sales & Stories & Blogs \\
\hline Marketing & Stories & Social media \\
\hline Roll out & Know-how & Video capture \\
\hline \multicolumn{3}{|l|}{ Review } \\
\hline Debriefing & Stories, Document creation & Narrativisation, visualisation \\
\hline Client report back & Surveys, reports and presentations & Document creation \\
\hline Archiving & Collation of KM forms from previous phases & Cloud-based document creation and archiving systems \\
\hline
\end{tabular}

$\mathrm{KM}$, knowledge management; ERP, enterprise resource planning; CRM, client relationship management. 


\section{Implications and recommendations}

It is recommended for SME KIO creative agencies to use the project lifecycle, which is a blueprint for all the activities within a project, to create appropriate $\mathrm{KM}$ systems for different forms of knowledge. It is also recommended for these businesses to have different forms of $\mathrm{KM}$ in the system rather than trying to retro-fit their existing activities into one type of KM.

As some of the literature on small KIO (Millar at al. 2016) suggests, the situational factors that this research uncovered might well apply to organisations operating on a larger scale. As such, the knowledge forms as the project lifecycle unfolds and the relevant $\mathrm{KM}$, here perceived on a micro scale, might be found to be the practical reality in many other organisations. The research would have to be taken further to test this supposition.

\section{Conclusion}

Many small creative agencies do not give active attention to KM. This study found that they do, however, see the value of archiving knowledge and sometimes admitted that KM might be critical to their survival. There are obstacles preventing KIO creative agencies from fully adopting an already existing KM IS. This study suggests that if one can delineate the different tasks in a project lifecycle and couple those with the knowledge forms produced in each, appropriate KM solutions could be offered that could more easily be incorporated into the already existing workflow.

\section{Acknowledgements}

Thanks to my supervisor, Elaine Garcia, for her assistance during this project. Thanks also to Prof. Roy Johnson for assisting in editing another version of this research.

\section{Competing interests}

The author has declared that no competing interest exist.

\section{Author's contributions}

The author is the sole contributor to the work.

\section{Funding information}

This research received no specific grant from any funding agency in the public, commercial or not-for-profit sectors.

\section{Data availability statement}

Data sharing is not applicable to this article as no new data were created or analysed in this study.

\section{Disclaimer}

The views and opinions expressed in this article are those of the author and do not necessarily reflect the official policy or position of any affiliated agency of the author.

\section{References}

Alavi, M. \& Leidner, D.E., 2001, 'Review: Knowledge management and knowledge management systems: Conceptual foundations and research issues', MIS Quarterly 25(1), 107-136. https://doi.org/10.2307/3250961

Al-Shammari, M., 2011, Knowledge management in emerging economies: Social, organisational and cultural implementation, Hershey, New York, NY.

Ambrosini, V. \& Bowman, C., 2001, 'Tacit knowledge: Some suggestions for operationalisation', Journal of Management Studies 38(6), 811-829. https://doi. org/10.1111/1467-6486.00260

Baltezarević, V., Baltezaravic, R. \& Jovanovic, J., 2015, 'Knowledge management as imperative for economic growth', Knowledge Management, EA 48(3-4), 62-68.

Baptista Nunes, M.B., Annansingh, F., Eaglestone, B. \& Wakefield, R., 2006, 'Knowledge management issues in knowledge-intensive SMEs', Journal of Documentation 62(1), 101-119. https://doi.org/10.1108/00220410610642075

Blankley, W.O. \& Booyens, I., 2010, 'Building a knowledge economy in South Africa', South African Journal of Science, viewed 26 February 2018, from http://www. scielo.org.za/scielo.php?pid $=$ S0038-23532010000600009\&script $=$ sci arttext\&tlng=en

Cerchione, E. \& Esposito, A., 2017, 'Using knowledge management systems: A taxonomy of SME strategies', International Journal of Information Management 37(1), 1551-1562. https://doi.org/10.1016/j.ijinfomgt.2016.10.007

Creswell, J.W., 2007, Qualitative inquiry \& research design: Choosing among five approaches, 2nd edn., Sage, New York, NY.

Creswell, J.W. \& Poth, C.N., 2018, Qualitative inquiry \& Research design: Choosing among five approaches, 4th edn., Sage, New York, NY.

Diedrich, A. \& Guzman, G., 2015, 'From implementation to appropriation: Understanding knowledge management system development and introduction as a process of translation', Journal of Knowledge Management 19(6), 1273-1294. https://doi.org/10.1108/JKM-02-2015-0055

Du Toit, A.S.A., 2003, 'Competitive intelligence in the knowledge economy: What is in it for South African manufacturing enterprises?', International Journal of Information Management 23(2), 111-120. https://doi.org/10.1016/S0268 4012(02)00103-2

Easterby-Smith, M., Thorpe, R. \& Jackson, P., 2012, Management research, 4th edn., Sage, London.

Ensor, J., Cottam, A. \& Band, C., 2001, 'Fostering knowledge management through the creative work environment: A portable model from the advertising industry', Journa of InformationScience27(3),147-155.https://doi.org/10.1177/016555150102700304

Eppler, M.J. \& Burkhard, R.A., 2007, 'Visual representations in knowledge management: Framework and cases', Journal of Knowledge Management 11(4), 112-122. https://doi.org/10.1108/13673270710762756

Fahey, L. \& Prusak, L., 1998, 'The eleven deadliest sins of knowledge management', California Management Review 40(3), 265-275. https://doi.org/10.2307/41165954

Farzaneh, N. \& Shamizanjani, M., 2014, 'Storytelling for project knowledge management across the project lifecycle', Knowledge Management and E-Learning 6(1), 83-97. https://doi.org/10.34105/j.kmel.2014.06.006

Garrick, J. \& Chan, A., 2017, 'Knowledge management and professional experience: The uneasy dynamics between tacit knowledge and performativity in organizations', Journal of Knowledge Management 21(4), 872-884. https://doi. org/10.1108/JKM-02-2017-0058

Heaton, L. \& Taylor, J.R., 2002, 'Knowledge management and professional work: A communication perspective on the knowledge-based organization', Management CommunicationQuarterly16(2),210-236.https://doi.org/10.1177/089331802237235

Khoza, L.T., 2019, 'Managing knowledge leakage during knowledge sharing in software development organisations', South African Journal of Information Management 21(1), 1-7. https://doi.org/10.4102/sajim.v21i1.1075

Kissling Hansen, J., 2009, 'How knowledge is transferred within the Danish Fashion Industry', Masters Thesis, Copenhagen Business School, viewed 25 October 2017 from http://studenttheses.cbs.dk/bitstream/handle/10417/618/jonas_kissling hansen.pdf.

Krylova, K.O., Vera, D. \& Crossan, M., 2016, 'Knowledge transfer in knowledgeintensive organizations: The crucial role of improvisation in transferring and protecting knowledge', Journal of Knowledge Management 20(5), 1045-1064. https://doi.org/10.1108/JKM-10-2015-0385

Lampel, J., Lant, T. \& Shamsie, J., 2000, 'Balancing act: Learning from organizing practices in cultural industries', Organisational Science 11(3), 263-269. https:// doi.org/10.1287/orsc.11.3.263.12503

Lapunka, I. \& Pisz, I., 2014, 'Knowledge management in the project life cycle: Initial research on Polish SMEs', Foundations of Management 6(2), 67-82. https://doi. org/10.1515/fman-2015-0012

Lawrence, T.W. \& Phillips, N., 2002, 'Understanding cultural industries', Journal of Management Inquiry11(4),430-441.https://doi.org/10.1177/1056492602238852

Madhavan, R. \& Grover, R., 1996, From embedded knowledge to embodied knowledge: New product development as knowledge management, Institute for the Study of Business Markets Report, Pennsylvania State University, viewed 23 October 2017 Business Markets Report, Pennsylvania State University, viewed 23 October 2017,
from https://pdfs.semanticscholar.org/f5b4/3a13449fb96b86bec28720a834979f from https://po

Marin, A., Cordier, J. \& Hameed, T., 2016, 'Reconciling ambiguity with interaction: Implementing formal knowledge strategies in a knowledge-intensive organization', Journal of Knowledge Management 20(5), 959-979. https://doi.org/10.1108/ Journal of Knowled
JKM-11-2015-0438 
McDermott, R., 1999, 'Why information technology inspired but cannot deliver knowledge management', California Management Review 41(4), 103-116. https://doi.org/10.2307/41166012

Millar, C.C.J.M., Lockett, M. \& Mahon, F., 2016, 'Guest editorial: Knowledge intensive organisations: On the Frontiers of Knowledge Management', Journal of Knowledge Management 20(5), 845-857. https://doi.org/10.1108/JKM-07-2016-0296

Nevo, D. \& Chan, Y.E., 2007, 'A Delphi study of knowledge management systems: Scope and requirements', Information \& Management 44(6), 583-597. https:// doi.org/10.1016/j.im.2007.06.001

Nissen, M.E., 2002, 'An extended model of knowledge-flow dynamics', Communication of the Association of Information Systems 8(2002), 251-266. https://doi. org/10.17705/1CAIS.00818

Nonaka, I. \& Takeuchi, H., 1995, The knowledge creating company: How Japanese companies create the dynamics of innovation, Oxford University Press, New York, NY.

Pina e Cunha, M. \& Da Cunha, J.V., 2006, 'Towards the improvising organisation', Business Leadership Review III(IV), 1-6.

Potgieter, A., Dube, T. \& Rensleigh, C., 2013, 'Knowledge management awareness in a research and development facility: Investigating employee perceptions', SA Journal of Information Management 15(2), Art. \#592, 6 pages, viewed 01 July 2019, from https://doi.org/10.4102/sajim.v15i2.592

Pratt, A.C. \& Jeffcutt, P. (eds.), 2009, Creativity, innovation and the cultural economy, Routledge, London.

Project Management Institute, 2018, What is project management, viewed 14 February 2018, from https://www.pmi.org/about/learn-about-pmi/what-isproject-management.

Roberts, J., 2000, 'From know-how to show-how? Questioning the role of information and communication technology in knowledge transfer', Technology Analysis \& Strategic Management 12(4), 429-443. https://doi.org/10.1080/713698499

Roblek, V., Bach, M.P., Mesko, M. \& Bertoncelj, A., 2013, 'The impact of social media to value added in knowledge-based industries', Kybernetes 42(4), 554-568. https://doi.org/10.1108/K-01-2013-0014
Sagsan, M., 2006, 'A new life cycle model for processing of knowledge management', in 2nd International Conference on Business, Management and Economics, Izmar.

Savino, T., Petruzzelli, A.M. \& Albino, V., 2017, 'Teams and lead creators in cultural and creative industries: Evidence from the Italian Haute Cuisine', Journal of Knowledge Management 21(3), 607-622. https://doi.org/10.1108/JKM-09-2016-0381

Scott, A.J., 2005, 'Cultural-products industries and urban economic development' Urban Affairs Review39(4), 461-490. https://doi.org/10.1177/1078087403261256

Snowball, J., 2016, 'Why art and culture contribute more to an economy than growth and jobs', The Conversation, viewed 2 March 2018, from https://theconversation. com/why-art-and-culture-contribute-more-to-an-economy-than-growth-andjobs-52224.

Soto-Acosta, P. \& Cegarra-Navarro, J., 2016, 'New ICTs for knowledge management in organizations', Journal of Knowledge Management 20(3), 417-422. https://doi org/10.1108/JKM-02-2016-0057

Steinmueller, W.E., 2000, 'Will new information and communication technologies improve the "Codification" of knowledge?', Industrial and Corporate Change 9(2), 361-376. https://doi.org/10.1093/icc/9.2.361

Taylor, J.R. \& Zorn, T., 2004, 'Knowledge management and/as organisational communication', International Communication Association, New Orleans, viewed 10 December 2017, from http://citation.allacademic.com/meta/p_mla_apa_ research_citation/1/1/2/4/2/p112428_index.html.

Teece, D.J., 1998, 'Research directions for knowledge management', Californic Management Review 40(3), 289-292. https://doi.org/10.2307/41165957

Tsoukas, H., 2002, 'Do we really understand tacit knowledge?', Knowledge Economy and Society Seminar, London, viewed 17 September 2017, from http://mba.eci. ufmg.br/downloads/dowereally.pdf.

Van Graan, M., 2005, Cultural industries, arts, culture and creative arts first paper: Towards an understanding of the current nature and scope of the creative industries in the Western Cape, viewed 21 February 2018, from https://www. westerncape.gov.za/other/2005/11/final_first_paper_cultural_industries printing.pdf. 